\title{
A SURVEY OF HOSPITAL ACQUIRED INFECTIONS IN OBAFEMI AWOLOWO UNIVERSITY TEACHING HOSPITAL, ILE-IFE
}

\author{
'Onipede, A. O., 'Oluyede, C.O., 'Aboderin, A. O., '2Zailani, S. B., \\ ${ }^{2}$ Adedosu, A. N., 'Oyelese, A. O., 'B Badmus T. A., ${ }^{3}$ Ikem, B.C., \\ ${ }^{2}$ Balogun, C. O., ${ }^{2}$ Olafimihan, K. F. \\ Departments of ${ }^{1}$ Medical Microbiology \& Parasitology, and ${ }^{3}$ Surgery \\ College of Health Sciences, Obafemi Awolowo University, lle-lfe \\ 2Department of Medical Microbiology and Parasitology, \\ Obafemi Awolowo University Teaching Hospital Complex lle-lfe
}

Correspondence to: Dr. A. O. Onipede (E-mail: aonipede@aouïte.edu.ng)

\begin{abstract}
A well-structured inféction control programme plays a vital role in reducing mortality, morbidity and cost resulting from nosocomial infections in hospitalized patients. However infection-control activities in developing countries is severely constrained by lack of infection control infrastructure and lack of strong commitment by hospital clinicians and administrators as well as the level of socio-political and economic development prevalent in the developing world. The infection Control Program (ICP) of Obafemi Awolowo University Teaohing Hospital Complex (OAUTHC) was established in 1995. An analysis of data of a hospital wide surveillance obtained between January 1995 and December 1999 is hereby presented, highlighting our experience with the pattern of nosocomial infection seen in this hospital. From January 1995 to December 1999, a total of 19,471 patients were discharged during this period. Of this, 515 cases of infection were recorded while on admission, giving an annual prevalence rate of $2.7 \%$ for nosocomial infection per year. $\left(X^{2}=47.34\right.$, $\left.\mathrm{df}=4, p=0.000\right)$. The highest infection rate was recorded from the orthopaedic ward $(12.8 \%)$, followed by the intensive care unit (ICU)(8.4\%) while the neonatal ward (NNW) and the paediatric ward (PW) recorded relatively low figures $(0.5 \%)$ and $(0.4 \%)$ respectively. Gram-negative rods (GNR) $491(78.8 \%$ ) were commonly encountered as pathogens implicated in hospital-acquired infection (HAl) followed by Staphylococcus aureus and "other" organisms $17(2.7 \%)$. Current methods are inadequate because phenotypic typing alone has limited discriminatory power. DNA typing method is now the 'gold' standard for epidemiological and routine investigation of HAI.
\end{abstract}

\section{INTRODUCTION}

A safe and appropriate health care delivery should be an important pre-occupation in hospitals.
One way of achieving this is the establishment of Infection Control Committees (ICC), which has the primary task to investigate and design measures to control all forms 
of Hospital Acquired Infection (HAI), thereby ensuring that nosocomial infections are within reasonable control. However, it is also true that the effectiveness of infection prevention and control depends largely on the level of sophistication of health care services and the prevalence of diseases (1).

Well-structured infection control has a vital role in reducing mortality, morbidity and cost resulting from nosocomial infections in hospitalized patients $(2,3)$. The United States Study on the Efficacy of Nosocomial Infection Control (SENIC) showed that a properly conducted program of surveillance and control could prevent $32 \%$ or nearly one third of cases $(1,4)$. Hence the incidence of HAI and the problem of resistant organisms are low in developed countries with well established infection control programs $(1,3)$. Whereas report from the developing countries south of the Sahara have put the nosocomial infection rate to vary from 3-15\% $(2,5)$, in Latin America, infection rate range from $10-26 \%$ with increased mortality and morbidity and a consequent economic burden $(2,6,7)$.

Moreover, infection control activities in developing countries are severely constrained by lack of infection control infrastructures and a strong commitment by hospital clinicians and administrators $(7,8)$, as well as the level of sociopolitical and economic development prevalent in the developing world (9). The Infection Control Program (ICP) of Obafemi Awolowo University Teaching Hospital Complex (OAUTHC) was established in 1995 with an Infection Control Team (ICT) reporting to an Infection Control Committee (ICC). An analysis of data of a hospital wide surveillance obtained between January 1995 and December 1999 is hereby presented, highlighting our experience with the pattern of nosocomial infection seen in this hospital and the challenges ahead.

\section{MATERIALS AND MITHODS}

A systematic program developed by the hospital but based on the Centres for Disease Control protocol and WHO $(2,5,9,10)$ for active surveillance for the collection routine input data was adopted by the hospital at the onset of infection control activities in 1995 to date. The hospital has 2 Infection Control Nurses (ICN) based primar- 
ily in the Medical Microbiology and Parasitology department. The ICN work closely with the Consultant Medical Microbiologist, who in turn reports the findings of the ICT to the ICC. The ICC is responsible for policy formulation and recommendation to the hospital. The hospital in Ile-Ife has a bed space of approximately 400 .

The microscopy, culture and sensitivity result of all specimens received in the laboratory are scrutinized by the ICN before the commencement of routine visit to the wards. The CDC guidelines for determining the presence and classification of infection, determine which event is HAI $(4,5)$. All specimens in the laboratory and bacterial agents associated with $\mathrm{HAI}$ were investigated by standard microbiological methods (12).

Primary data were collected with the aid of forms, designed for active surveillance. This contained essential identifying data like patient's name, age, sex, hospital identification number, ward or location within the hospital, service and date of admission. Others are date set of infection, the site of infection, and the organism(s) isolated from specimens and antimi- crobial susceptibility pattern of isolates. Monthly summary constitutes secondary data and the fol-. lowing are considered essential: service unit, site of infection and causative agent(s). These are further analyzed at the end of every year to generate a third level of data for the overall frequency and distribution pattern of HAI in our hospital, which is the basis of the present report.

\section{RESULTS}

From January 1995 to December 1999 , a total of 19,471 patients who were previously on admission for various ailment or disease conditions were discharged during this period. Of this, 515 cases of infection were recorded while on admission, giving a prevalence rate of $2.6 \%$ of infection per patient discharged per year $\left(x^{2}=\right.$ $47.34 \mathrm{df}=4, \mathrm{p}=0.000$ ). Table I shows a break down and the prevalence of HAI by year. The highest infection rate was recorded in 1996 (3.6\%) and the lowest was 1991 $(1.2 \%)$, while Table II shows the summary and trend of infection according to service unit. The highest infection rate was recorded from the orthopaedic ward $(12.8 \%)$, fol- 
lowed by the intensive care unit $(8.4 \%)$ while the neonatal ward (NNW) and the paediatric ward (PW) recorded relatively lower figures $(0.5 \%$ and $0.4 \%)$ respectively. The pattern of HAI by service area is summarized in Table III. When the frequency and type of infection were compared, wound infection from the surgical service units was highest with $260(50.5 \%)$, next was urinary tract infection (UTI) 204 $(39.6 \%)$ followed by bacteraemia 34 (6.6\%). Respiratory infections and miscellaneous infections were 5 $(1.0 \%)$ and $12(2.3 \%)$ respectively. However, when the patterns of HAI between surgical and medical services were compared, Chi square showed a significant difference $\left(\mathrm{X}^{2}\right.$ $=46.4$, df $4, p<0.05$ ).
Table IV shows the frequency of pathogens and hospital associated infections. Gram-negative rods (GNR) 491(78\%) were commonly encountered as pathogens implicated in HAI, followed by $S$. aureus $115(18.5 \%)$ and 'other' organisms $17(2.7 \%)$. The individual Gram negative rods implicated in $\mathrm{HAI}$ is shown in Table $\mathrm{V}$. The highest recoverable pathogen was from the genus Pseudomonas 1693(4.4\%), followed by Klebsiella 151(30.8\%), Proteus $84(17.1 \%)$ and Escherichia $58(11.8 \%)$ successively while the least was Citrobacter $3(0.6 \%)$. Gram-negative pathogens that presented difficulty with identification were reported as 'coliform 26 $(5.3 \%)$. Figure $A$ is a histogram illustrating Gram- negative rods and HAI.

\section{Table 1: INCTDENCE AND PATTERN OF NOSOCOMIAL INFECTION IN OAUTHC ILE IFE}

\begin{tabular}{|c|c|c|}
\hline YEAR & NUMBER OF DISCHARGE & NUMBER OF INFECTIONS N(\%) \\
\hline 1995 & 4805 & $107(2.2 \%)$ \\
\hline 1996 & 3411 & $122(3.6 \%)$ \\
\hline 1997 & 4185 & $127(3.0 \%)$ \\
\hline 1998 & 3703 & $119(3.2 \%)$ \\
\hline 1999 & 3367 & $40(1.2 \%)$ \\
\hline TOTAL & 19471 & $515(2.6 \%)$ \\
\hline
\end{tabular}

$$
X^{2}=47.34, \mathrm{df}=4, \mathrm{P}=0.000
$$


Table 2: SUMMARY AND TREND OF INFECTION BY SERVICE

\begin{tabular}{|c|c|c|}
\hline SERVICE & DISCHARGES & INFECTION \\
\hline SURGICAL WARD & 3670 & $150(4.1 \%)$ \\
\hline ORTHOPAEDIC WARD & 876 & $112(12.8 \%)$ \\
\hline OBST \& GYNAE & 5531 & $138(2.5 \%)$ \\
\hline MED. WARD & 3961 & $68(1.7 \%)$ \\
\hline PAED & 3638 & $15(0.4 \%)$ \\
\hline NNW & 1498 & $7(0.5 \%)$ \\
\hline ICU & 297 & $25(8.4 \%)$ \\
\hline TOTAL & 19471 & $515(2.6 \%)$ \\
\hline
\end{tabular}

Table 3: PATTERN OF HAI SERVICE AREA 1995-1999

\begin{tabular}{|c|c|c|c|c|c|}
\hline SERVICE & BACTEREMIA & $\begin{array}{c}\text { WOUND } \\
\text { INFECTION }\end{array}$ & UTI & $\begin{array}{c}\text { RESPIRA- } \\
\text { TORY } \\
\text { INFECTION }\end{array}$ & OTHERS \\
\hline SURGICAL WARD & 7 & 77 & 54 & 3 & 9 \\
\hline ORTHO WARD & - & 85 & 25 & 2 & - \\
\hline OBST WARD & 1 & 72 & 65 & - & - \\
\hline MED. WARD & 12 & 10 & 46 & - & - \\
\hline PAED WARD & 9 & 2 & 4 & - & - \\
\hline NEONATAL & 4 & - & 3 & - & - \\
\hline ICU & 1 & 14 & 7 & - & 3 \\
\hline TOTAL & 34 & 260 & 204 & 5 & 12 \\
\hline $515(100 \%)$ & $(6.6 \%)$ & $(50.5 \%)$ & $(39.6 \%)$ & $(1.0 \%)$ & $(2.3 \%)$ \\
\hline
\end{tabular}

$X^{2}+46.4, d f=4, P=0.000(p<0.005)$

* For the purpose of analysis "surgical ward", "orthopaedic ward" and "Gynaecology" were combined as surgical, Medical ward and Paediatric ward were combined as Medical and Neonatal and ICU were also combined.

** The columns "Respiratory infections" and "others" were not included in the analysis due to the small number of samples in these groups. 
Table 4: HOSPITAL ASSOCIATED INFECTIONS BY SITE AND PATHOGEN 1995-1999

\begin{tabular}{|c|c|c|c|}
\hline & GRAM NEGATIVE & S. aureus & *OTHERS \\
\hline BACTEREMIA $(\mathrm{n}=34)$ & 17 & 16 & 2 \\
\hline $\begin{array}{c}\text { WOUND INFECTION } \\
(\mathrm{n}=260)\end{array}$ & 286 & 83 & 14 \\
\hline UTI $(\mathrm{n}=204)$ & 177 & 16 & - \\
\hline RESPIRATORY $(\mathrm{n}=5)$ & 6 & - & - \\
\hline OTHERS $(\mathrm{n}=5)$ & 5 & - & 1 \\
\hline TOTAL 515 & 491 & 115 & 17 \\
\hline
\end{tabular}

*Others

Coagulase negative Staphylococcus $=9$

Streptcoccis faecalis $=8$

Table 5: GRAM NEGATIVE RODS IMPLICATED IN HAI 1995-1999

\begin{tabular}{|c|c|c|c|c|c|c|}
\hline \multirow{2}{*}{ ORGANISM } & \multicolumn{7}{|c|}{ YGAR } \\
\cline { 2 - 7 } & 1995 & 1996 & 1997 & 1998 & 1999 & TOTAL \\
\hline PSEUDOMONAS SPP. & 42 & 40 & 39 & 27 & 21 & $169(34.4 \%)$ \\
\hline KLEBSIELLA SPP. & 28 & 40 & 35 & 39 & 9 & $151(30.8 \%)$ \\
\hline PROTEUS SPP. & 27 & 16 & 18 & 22 & 1 & $84(17.1 \%)$ \\
\hline CITROBACTER & 1 & - & 1 & 1 & - & $3(0.6 \%)$ \\
\hline E. COLI & 14 & 13 & 15 & 14 & 2 & $58(11.8 \%)$ \\
\hline COLIFORM & 4 & 6 & 10 & 4 & 2 & $26(5.3 \%)$ \\
\hline & $*$ & $*$ & $*$ & $*$ & $*$ & $491(100 \%)$ \\
\hline
\end{tabular}




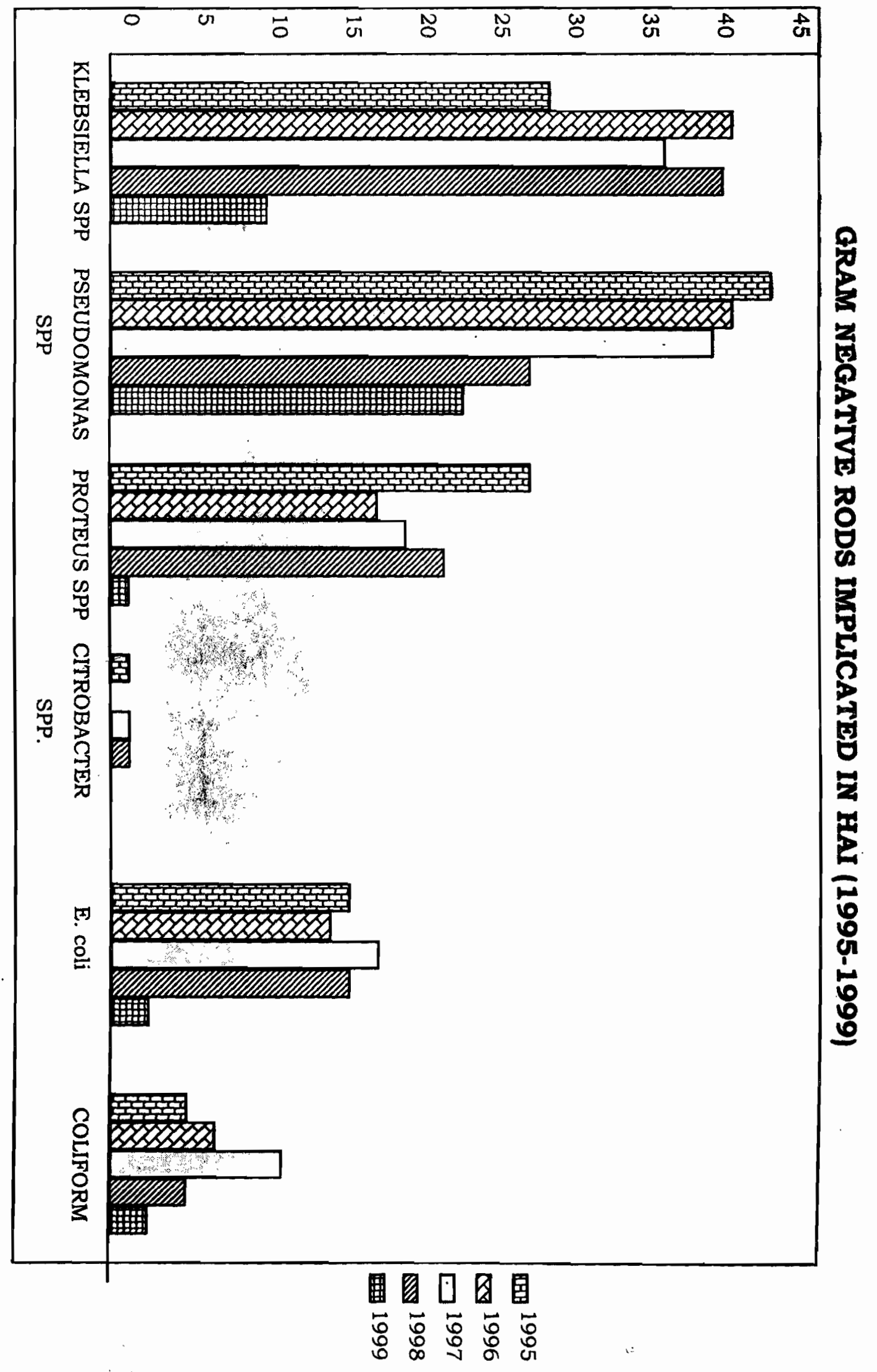

Pg. 114-6s 


\section{DISCUSSION}

The ultimate objective of establishing an ICP in any hospital is to translate surveillance efforts into infection prevention $(1,5)$. In our experience, the overall average prevalence rate of HAI in this hospital is $2.6 \%$. This figure is low when compared with $3.78 \%$ reported by Ogunsola et al (13) for Lagos University Teaching Hospital, and lower still for annual prevalence rate of $3-15 \%$ reported for hospitals in developing countries $(5,6)$. Differences in matters of protocols and standard definition of cases of nosocomial infection may be responsible for differences in prevalence rate from one hospital to another which make a direct comparison difficult (4). This is why the CDC definition of nosocomial infection includes clinical and laboratory information and requires updating (2). However the investigation of HAI has been greatly aided by the development of DNA typing methods in the developed countries, tools that are currently not available to us at the moment.

Urinary tract infection (UTI) is the most common form of $\mathrm{HAI}$ accounting for between 30-45\% $(10,15)$, however, in our survey,
UTI accounted for $39.6 \%$ of $\mathrm{HAI}$ after wound infection, which was $50.5 \%$. Nearly all nosocomial UTI occurred in patients with recognized risk factors, such as urethral catheterization and other forms of instrumentation $(13,15,16)$, this was also the case in our experience. The surgical service department recorded a high frequency of wound infection compared to the medical departments. This observation may reflect the extreme factors before, during and after operation of patients seen during this period. A prospective study done in this hospital on postoperative wound infection, reported an infection rate of $15.1 \%$ (17). However, this was restricted to general survey without orthopaedic and obstetrics and gynaecological cases taken into consideration, which are included in this survey. Our observation on the pattern of vround infections is consistent with report from other developing countries (16).

Bacteraemia as a form of $\mathrm{HAI}$ is most often secondary to urinary, surgical wound or lower respiratory tract infection, or to extra luminal cannular related sepsis (5). We observed that bacteraemia accounted 
for $6.6 \%$ of total $\mathrm{HAl}$ seen in our hospital while a study from Trinidad and Tobago reported 8\% (11). The underlying disease condition in the patients may have contributed to the observed level of bacteraemia in this survey.

Gram-negative rods were more implicated in $\mathrm{HAI}$ in this survey, more commonly, Pseudomonas spp, which is a recognized opportunistic pathogen in the hospital setting. The pattern of hospital associated infections by site and pathogen is similar to what has been reported by other studies $(5,6,7,16)$. Fig. A shows modest achievement recorded on individual Gram-neyative rods from 19951999 due to intervention method instituted like hand washing, increased disinfectant and soap rations to the wards and personal contacts to the clinical service departments.

Our survey shows that we need to improve on our infection control infrastructure and to encourage strict adherence to infection control practices such as hand washing techniques and improvement of facilities in the hospital environment (18). Finally, the effective prevention and control of $\mathrm{HAI}$ in the developing countries lies in the introduction and application of molecular epidemiology into surveillance activities. Current methods are inadequate because phenotypic typing alone has limited discriminatory power. DNA typing method is now the 'gold' standard for epidemiological and routine investigation of $\operatorname{HAI}(16,19)$.

\section{REFERENCE}

(1). Wenzel RP. Towards a global perspective of nosocomial infections. Eur. J. Clin. Microbiol. 1987; 6: 341-343

(2). Starling CE, Couto BR, Pinheiro SM. Applying the centers for Diseases Control and Prevention and National Surveillance System Methods in Brazilian Hospitals. Am. Ch Infect. Contr. 1997; 25: 303-311.

(3). Managan LP, Aschibald LK, Pearson ML. Selected global health care activities of the Hospital Infections Program, Centers for D i s ease Control and Prevention. Am. J. Infect. Contr. 1999; 27: $270-274$. 
(4): Starling CEF, Couto BRMF, Pinheiro SMC. Multi centre study of the definitions of nosocomial infections [abstract]. In Abstracts of the $4^{\text {th }}$ Decennial International Conference on Nosocomial and Health care. Associated infections; 5-9 March 2000, Atlanta, Georgia. Infect. Contr. Hosp. Epidemiol. 2002: 21-153.

(5). Haley RW, Culver DH, White $J W$. The efficacy of infection surveillance and control programs in preventing nosocomial infection in US hospitals. Am. J. Epidemiol. 1985; 121: $206-215$.

(6). Pannuti CS, Grnbaum RS. An overview of nosocomial control in Brazil. Infect. Contr. Hosp. Epidemiol. 1995; 16(3): 170-174.

(7). Forder AA. Infection Control: a challenge in the land of contrast. J. Hosp. Infect. 1993; 3: 87-94.

(8). Ponce-de leon S, Rangelfrausto MS, Elias-Lopez JI, Romero- Oliveros C, Huertas-Jimenez $M$. Nosocomial Infections: secular trends of a control program in Mexico. Salud. Publica. Mex.1999; 41(Suppl 1): S5-S11.
(9). Rhinehart E, Goldman DA, O' Rourke IJ. Adaptation for the prevention of nosocomial infection in a paediatric intensive care unit in Jakarta, Indonesia. Am. J. Med. 1991; 91 (3B): 213S- $220 \mathrm{~S}$.

(10). Meers PD. Infection control in developing countries. J. Hosp. Infect. 1988; 11 (Suppl A): $406-10$.

(11). Jarvis WR. Handwashing- the Semmelweis lesson forgotten? Lancet. 1994; 344 (8933): 1311-1312.

(12). Cowan ST. Cowan and Steel's manual for the identification of medical bacteria. $2^{\text {nd }}$ ed. Cambridge University Press: 1985.

(13). Ogunsola FT, Coker AO, Adetunji A, Iregbu KC. Infection control in the Lagos University Teaching Hospital: Problems and strategies for improvement. In Abstracts of the 1st International conference on Nosocomial and Infection Control in Africa. Paper 5. 1995.

(14). Makombe K. Infection Control in the rural community in Zimbabwe. Infect. Contr. $J$. Southern Africa. 1997; 2: 2630. 
(15). Meers C, Toffelmire EB, McMurray M, Hopman W. Reducing complications during haemodialysis using gradient ultrafiltration with gradient sodium dialysate. ANNA J. 1999; 26 (5): 495-500 discussion 501,505 .

(16). Lawal OO, Adejuyigbe O, Oluwole SF. The predictive value of bacterial contamination. at operation in post-operative wound sepsis. Afr. Med. Sci. 1990; 19(3): 173-179.
(17). Neuman MJ. Infection Control South of the Sahara. Infect. Contr. Hosp. Epidemiol. 2001; 22: 68-68.

(18). Jarvis WR. Usefulness of molecular epidemiology for the outbreak investigation. Infect. Contr. Hosp. Epidemiol. 1994; 15(7): 500-503.

(19). Bingen E. Applications of molecular methods to epidemiological investigations of nosocomial infection in a paediatric hospital. Infect. Contr. Hosp. Epidemiol. 1994; 15 (7): 488-493 